\title{
Adaptation of methods for the determination of biodegradation of bio-textiles with amber particles
}

\author{
Ilze Dubova*1, Agnija Apine', Dace Grauda1', Dalius Butkauskas", \\ Inga Lashenko ${ }^{3}$, Līga Jankevica ${ }^{1}$ \\ 1 Institute of Biology, University of Latvia, Ojära Vācieša street 4, Riga, Latvia, LV-1004 \\ 2 Nature Research Centre, Akademijos Street 2, LT-08412, Vilnius, Lithuania \\ 3 LU Technologies Ltd, Ilūkstes street 107/1-16, Riga, Latvia, LV-1082 \\ * Corresponding author: ilze.dubova@lu.lv
}

\begin{abstract}
One of the criteria for bio-textiles is the potential for biodegradation. Our goal was to adapt methods for the determination of biodegradation of bio-textiles containing amber particles. We adapted methods EN ISO 11721-1: 2001 and ISO 11721-2: 2003 developed for the study of interaction of cellulose - containing textiles and microorganisms.

To determine the changes of fabrics, the mechanical properties and level of biodegradation were examined. Experiments revealing level of biodegradation of bio-textile were carried out at the Institute of Biology, University of Latvia while mechanical properties were tested at the Scientific Laboratory of Mechanics and Bio-textiles of the Institute of Mechanics and Mechanical Engineering, Riga Technical University. The study was financially supported by the EUREKA project E!11170 "Innovative multifunctional bio-textile, integrated with silica dioxide and succinate development, and its impact on biosystems" (IFSITEX).
\end{abstract}

Keywords: deterioration, biofragmentation, soil burial test

\section{Introduction}

One of the criteria for bio-textiles is the potential for biodegradation. Over the last 50 years, global production of synthetic fibres has grown rapidly, which are non-biodegradable and, at best, recyclable, and reusable. Over time, these materials must be incinerated, buried, or disposed of in an aquatic environment, which is not an environmentally friendly solution. Therefore, biodegradation is becoming more and more important as it converts materials into water, carbon dioxide and biomass that do not harm the environment (Arshad et al., 2014). Biodegradation is the process by which a material is physically, chemically, or 
biochemically irreversibly broken down into elements Deterioration of the structure, bio-fragmentation and assimilation accrue during process of biodegradation. It has been studied that cellulose and non-cellulose materials degrade similarly, differing in biodegradation time. During the bio-fragmentation process, microorganisms develop enzymes, as well as free radicals, which break down macromolecules into smaller units (Dulik et al., 2010). Biodegradability of cellulose fibers, as in other textile materials, could be measured by soil burial test, activated sludge test, and enzymatic hydrolysis test (Park et al., 2004). Gaidukovs and coleagues (2016) reported that succinate has an extremely high number of organic compounds of enormous chemical diversity, therefore evaluation of the effect of incorporated amber particles to bio-textiles affecting biodegradability of textiles deserves special attention.

Our goal was to adapt methods for the determination of biodegradation of biotextiles with incorporated amber particles based on modifications of the regular soil burial test ISO 11721-1 (2001), and long-term burial test ISO 11721-2 (2003). The assessment of biodegradation level was based on comparison of fabric changes including mechanical properties (determination of tensile strength) and visual changes of tested specimens.

\section{Materials and methods}

\section{Test specimens}

Fabric stripes of raw materials produced by A/B Linas (LT) \& JLU Technologies Ltd. (LV) were used in tests:

- unfinished - cotton / linen (code CL564T, WARP: linen 28 Tex WEFT: cotton 20 Tex, Twill interlacing)

- bio-textile - cotton / linen with amber particles (code CL561T, WARP: linen 28 Tex, WEFT: cotton 20 Tex plus amber 7.8 Tex, Twill interlacing).

Cotton fabrics were used for control.

The specimens were prepared from the middle of the samples of fabric by cutting the cloth strips lengthwise from the warp direction of the fabric and cut 300 $\mathrm{mm}$ long and $30 \mathrm{~mm}$ wide and then fray down both sides to give a central width of $20 \mathrm{~mm}$. For each fabric 20 test specimens were prepared, 10 for testing without burial and 10 testing after soil burial.

\section{The determination of degradation activity of test soil}

Industrially produced compost mixture (60\% compost, $40 \%$ high bog peat) produced UAB "Juknevičiaus kompostas" (Lithuania) was used. The $\mathrm{pH}$ of the test soil was 6.45 . Water content (WC) $60 \pm 5 \%$ of the water-holding capacity (WHC) of soil mixture was determined by drying the soil sample at the temperature of 
$104 \pm 1{ }^{\circ} \mathrm{C}$ until constant mass is obtained. Calculations and correction of water content of test soil was done before and after test. When the soil was too dry, we added $2.5 \mathrm{ml}$ water on $100 \mathrm{~g}$ soil and replaced any losses during burial test.

Containers - unglazed pottery (15 cm deep) - with $750 \mathrm{~g}$ of soil mixture were used to bury the specimens. In each container were placed 10 specimens in a U-form to evenly contact the soil and container covered with aluminium folia. Incubation was done at $30{ }^{\circ} \mathrm{C} \pm 1{ }^{\circ} \mathrm{C}$ in climatic chamber with $95-100 \%$ humidity. The cloth strips were removed at one-day intervals, lightly rinsed with running tap water, and immersed in $70 \%$ ethanol for 30 min before drying at $45^{\circ} \mathrm{C}$ in thermostat for 24 hours.

\section{The burial of test specimens}

We adapted the regular soil burial test (ISO 11721-1, 2001) and long-term burial test (ISO 11721-2, 2003). The buried fabric strips were removed from containers at intervals of four days for regular burial test and at intervals 8,16 and 28 days for long-term burial test.

To determine the leaching effect on biodegradation, the leaching procedure of test specimens was done before burial procedure according to ISO 11721-1 (2001). The test specimens were held under fresh running tap water at $20 \pm 5{ }^{\circ} \mathrm{C}$ for $24 \mathrm{~h}$ and dried at $45 \pm 5^{\circ} \mathrm{C}$ for $24 \mathrm{~h}$. Test specimens, both leached and unleached were treated in parallel.

All specimens after removing from soil were treated analogous, lightly rinsed with running tap water and immersed in $70 \%$ ethanol for $30 \mathrm{~min}$ before drying at $45^{\circ} \mathrm{C}$ in thermostat for 24 hours.

\section{Determining the breaking strength of buried test specimens}

Mechanical properties of buried and unburied textiles were analysed in Scientific Laboratory of Mechanics and Bio-textiles of the Institute of Mechanics and Mechanical Engineering, Riga Technical University. Breaking strength of the textile samples (after biological degradation) were examined in accordance with EN ISO 13934-1 (2013) on the Universal Testing Machine Zwick / Roell Z150, GE. Zwick / Roell testing machine was used in testing areas of cleanroom class 6 .

\section{Visual evaluation of fabric changes during biodegradation}

Size of buried specimens (width, length, thickness $(\mathrm{mm})$ was tested. The buried specimens were observed using a microscope (magnification 30x and 50x). Colour changes, partial or complete removal of cellulose fibers, appearance in transmitted light, disruption of surface structure is evaluated according to ISO 11721-2 (2003). Comparison was done between corresponding test specimens:

a) unburied unleached with buried unleached;

b) unburied leached with buried leached. 
Fabric changes and the degree of damage were evaluated on a five-point scale, were,

0 - not visible surface structural changes at 50x magnification.

1 - not visible surface structure changes without magnification, but visible under a microscope, light changes in color.

2 - visible surface structure changes without magnification, 25\% surface changes in color and thickness, visible changes in appearance of transmitted light.

3 - visible surface structure damages without magnification, up to $50 \%$ surface changes in color and thickness, visible changes in appearance of transmitted light.

4 - significant surface structure damages without magnification, more than $50 \%$ surface changes in color and thickness, partial removal of cellulose fibers, strong transmitted light.

5 - strong surface structure damages, strong colour changes, complete removal of cellulose fibers, a fabric are fragmented un small parts.

The obtained data were analysed using a Wilcoxon test.

\section{Results and Discussion}

\section{Determining the degradation activity of test soil}

Due to the biological nature of the soil burial test, and the fact that the test soil cannot be precisely standardized, it is only intended to assess the resistance of fabric to micro-organisms after comparing the performance of specimens. We determine the level of microbial soil activity accordingly ISO 11721-1 (2001), using control cotton and linen specimens and a defined incubation period.

Decreasing ratio (\%) in tensile strength of degraded samples was measured by soil burial test and the results are presented in Table 1. The cotton and linen fabric specimens lost more than $80 \%$ from maximum tensile strength after six-day burial. In this experiment, linen showed the highest biodegradability. This may probably be because linen has the largest portion of noncellulose ingredients, including lignin (Parks et al., 2004). 
Table 1. Decreasing ratio (\%) in tensile strength of degraded control samples after incubation in soil $\left(+29^{\circ} \mathrm{C}\right)$

\begin{tabular}{|l|c|c|c|}
\hline \multicolumn{1}{|c|}{ Test specimens } & $\begin{array}{c}\text { Exposure in soil } \\
\text { (days) }\end{array}$ & $\begin{array}{c}\text { Breaking strength, } \\
\text { (P) N } \pm \text { SD }\end{array}$ & Decreasing ratio (\%) \\
\hline cotton fabric & 0, unburied & $88.1 \pm 2.9$ & \\
\hline cotton fabric & 2 & $68.3 \pm 0.9$ & 32.4 \\
\hline cotton fabric & 3 & $53.9 \pm 6.5$ & 39.0 \\
\hline cotton fabric & 4 & $38.7 \pm 10.4$ & 56.1 \\
\hline cotton fabric & 5 & $26.7 \pm 5.3$ & 69.7 \\
\hline cotton fabric & 6 & $16.5 \pm 0.7$ & $\mathbf{8 1 . 3}$ \\
\hline linen fabric & 0, unburied & $212 \pm 8.17$ & 39.6 \\
\hline linen fabric & 3 & $128 \pm 2.2$ & 67.7 \\
\hline linen fabric & 4 & $69 \pm 5.2$ & 77.4 \\
\hline linen fabric & 5 & $48 \pm 4.7$ & $\mathbf{9 1 . 0}$ \\
\hline linen fabric & 6 & $19 \pm 1.3$ & \\
\hline
\end{tabular}

\section{The burial of test specimens}

For the regular burial test, according to determined soil biological activity, we use an incubation period of four days, for long term burial test 8,16 and 28 days. Tensile strength before burial of biotextile with amber particles $(162.6 \mathrm{~N})$ was higher than unfinished $(140.7 \mathrm{~N})$ and controle specimens - cotton fabrics $(84.5 \mathrm{~N})$.

We determined that the tensile strength of biotextile (cotton / linen with amber particles, code CL561) and unfnished (cotton/linen, code T564) before burring procedure did not differ significantly $(P>0.05)$ (Table 2$)$. Tensile strength of cotton, biotextile with amber particles and unfinished specimens after four days of incubations in soil decreased by $57.9 \%, 58.9 \%$ and $65.4 \%$, respectively.

The leaching procedure did not significantly affect the biodegradation processes of cotton fabrics. Leacing of biotextiles with amber particles and unfnished specimens increased loss of tensile strength after four-days burring 1.8-1.9 times (Table 2).

After eight-day biodegradation, cotton fabric specimens had already broken down in pieces, and it was not possible to determine the tensile strength. Tensile strength of unleached bio-textile with amber particles and unfinished specimens after 8 days was in range 2.5-2.7 N. Tensile strength of leached bio-textile with amber particles and unfinished specimens after 8 days was in range 1.2-2.4 N. The presence of amber particles does not significantly affected the biodegradation process as the difference between controls is less than 25\%. After burial fabric specimens in soil 16 and 28 days, fabrics had already broken down in small pieces and only visual evaluation was possible. 
Table 2. The tensile strength of unleached and leached specimens after burial in soil (incubation 4, 8, 16 days)

\begin{tabular}{|c|c|c|c|c|c|}
\hline $\begin{array}{c}\text { Test } \\
\text { specimens }\end{array}$ & $\begin{array}{c}\text { Incubation } \\
\text { period (days) }\end{array}$ & $\begin{array}{l}\text { Breaking } \\
\text { strength } \\
\text { (P) } \mathrm{N} \pm \mathrm{SD} \\
\text { (without } \\
\text { leaching) }\end{array}$ & $\begin{array}{c}\text { Decreasing } \\
\text { ratio (\%) }\end{array}$ & $\begin{array}{l}\text { Breaking } \\
\text { strength } \\
\text { (P) } N \pm S D \\
\text { (with } \\
\text { leaching) }\end{array}$ & $\begin{array}{c}\text { Decreasing } \\
\text { ratio (\%) }\end{array}$ \\
\hline \multirow{3}{*}{$\begin{array}{l}\text { cotton } \\
\text { fabrics }\end{array}$} & $\begin{array}{l}0 \text { (control, } \\
\text { unburied) }\end{array}$ & $84.5 \pm 6.7$ & & $80.6 \pm 7.2$ & \\
\hline & 4 (f1) & $35.6 \pm 8.9$ & 57.9 & $38.6 \pm 11.7$ & 52.1 \\
\hline & $8(f 2)$ & $\#$ & \# & \# & $\#$ \\
\hline \multirow{3}{*}{$\begin{array}{l}\text { unfinished } \\
\text { (cotton/ } \\
\text { linen) }\end{array}$} & $\begin{array}{l}0 \text { (control, } \\
\text { unburied) }\end{array}$ & $146.1 \pm 7.9$ & & $156.7 \pm 14.7$ & \\
\hline & $4(f 1)$ & $47.9 \pm 12.3$ & 65.9 & $27.1 \pm 8.8$ & 82.7 \\
\hline & $8(f 2)$ & $2.7 \pm 1.8$ & 99.3 & $2.4 \pm 1.4$ & 99.4 \\
\hline \multirow{3}{*}{$\begin{array}{l}\text { bio-textile } \\
\text { (cotton / } \\
\text { linen with } \\
\text { amber } \\
\text { particles) }\end{array}$} & $\begin{array}{l}0 \text { (control, } \\
\text { unburied) }\end{array}$ & $162.8 \pm 22.7$ & & $154.9 \pm 21.2$ & \\
\hline & $4(f 1)$ & $67.8 \pm 11.2$ & 58.3 & $34.9 \pm 7.9$ & 77.5 \\
\hline & $8(f 2)$ & $2.5 \pm 1.1$ & 99.6 & $1.2 \pm 0.5$ & 99.4 \\
\hline
\end{tabular}

\section{Visual evaluation of fabric changes during biodegradation}

After four days burial in soil, fabric specimens have changes in surface structure which are visible without magnification. In most cases fabric surface changes in color were in range from $25 \%$ to $50 \%$ (Figure 1). After 8 days using magnification, we were able to observe that microorganisms, including fungi, appeared on the surface of the fibres. Unfinished cotton / linen specimens had more visible fungi than other samples and exhibited the most serious shape deformation caused by fibre damage.

Colour changes, partial or complete removal of cellulose fibres, appearance in transmitted light, disruption of surface structure of buried specimens was evaluated using five - point scale. After visual assessment of the fabric surface structure for samples, the average score obtained after 4 days burial in soil ranged from 1.4 to 2.6 points. Bio-textiles had the lowest surface structure damages - 1.4 points, and significantly differ $(P<0.05)$ from other specimens. 
Fabric specimen surface damage estimates ranged from 2.8 to 3.8 points after 8 days of burial and from 3.6 to 4.6 points after 16 days burial. After 28 days all specimens had strong surface structure damages and ranged from 4.8 to 5.0 points. After 8 days we were able to observe that microorganisms including fungi appeared on the surface of the fibres. Unfinished cotton / linen specimens have more visible fungi than other samples and exhibited the most serious shape deformation caused by fiber damage. We did not observe significant differences between specimens after burial 8,16 and 28 days.
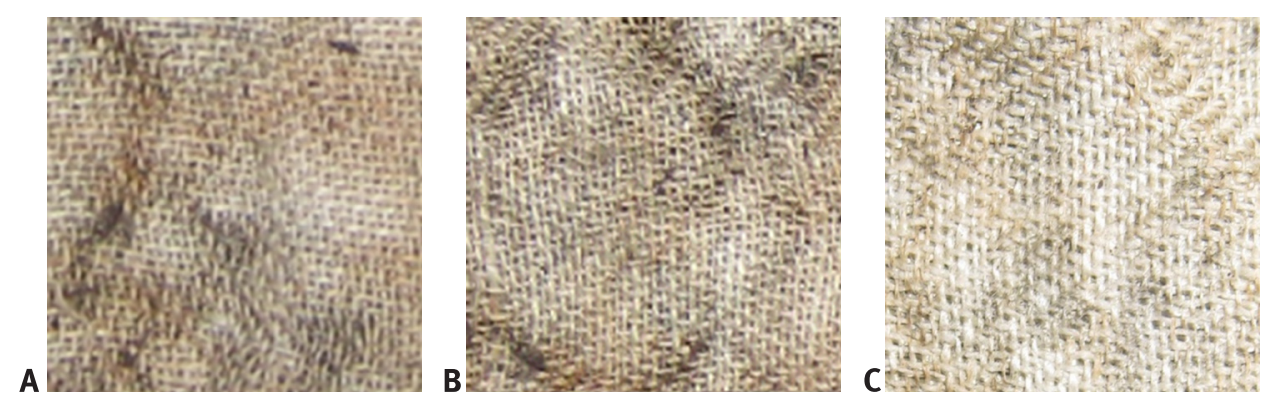

Figure 1. Visual changes of test specimens buried in soil for 4 days $\left(29^{\circ} \mathrm{C}, 95-100 \%\right.$ humidity). Test specimens: A - cotton fabrics; B - unfinished specimens (cotton/linen; code T564); C - bio-textile specimens (cotton /linen with amber particles, code CL561).

The performed experiments showed that the selected methods could be successfully used for determination of biodegradability of new developed materials inciuding bio-textile fabric with incorporated amber particles. Both selected methods (determination of tensile strength and visual evaluation of fabric surface changes during biodegradation) showed that the biodegradation of bio-textiles is significantly lower after four days. The biodegradability of the textiles over a longer period does not differ significantly between the tested specimens.

Although this study provides positive results on the biodegradation of bio-textiles with amber particles, further research is needed on the practical applicability of amber in the production of bio-textiles.

\section{Acknowledgements}

The study was financially supported by the EUREKA project E!11170 "Innovative multifunctional bio-textile, integrated with silica

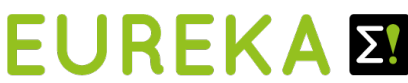
innovation across borders biosystems" (IFSITEX!). 


\section{References}

Arshad, K., Mujahid, M. 2011. Biodegradation of Textile Materials. Boras: The Swedish School of Textiles, pp. 14-22.

Dulik, F., Janda, K., and Wypych, G. 2010. Handbook of Material Biodegradation, Biodeterioration, and Biostablization. $1^{\text {st }}$ Edition. Toronto: ChemTec Publishing, pp. 15-19.

Gaidukovs, S., Lyashenko, I., Rombovska, J., and Gaidukova, G. 2016. Application of amber filler for production of novel polyamide composite fiber. Textile Research Journal. 86(20): 2127-2139.

ISO 11721-1:2001. Textiles - Determination of resistance of cellulose-containing textiles to microorganisms - Soil burial test - Part 1: Assessment of rot-retardant finishing. P. 16.

ISO 11721-2:2003. Determination of the resistance of cellulose-containing textiles to microorganisms - Soil burial test - Part 2: Identification of long-term resistance of a rot retardant finish. P. 7.

ISO 13934-1: 2013. Textiles - Tensile properties of fabrics -Part 1. Determination of maximum force and elongation of maximum force at maximum force using the strip method.

Park, C. H., Kang, Y. K., and Im., S. S. 2004. Biodegradability of Cellulose Fabrics. Journal of Applied Polymer Science. 94: 248-253. 